\title{
FINITE ELEMENT ANALYSIS OF STATOR LINING OF SCREW DRILL
}

\author{
Y.Q. Xia* \\ SWPU, Cengdu, China
}

\author{
H.M. Sun \\ SWPU, Cengdu, China
}

\author{
T.Y. Shang \\ SWPU, Cengdu, China
}

\begin{abstract}
The rubber bushing of screw drilling tool is the weak part of motor in drilling work. It is divided into conventional stator rubber bushing and equal wall thickness rubber bushing. The main material is NBR. With the help of large-scale finite element analysis software ABAQUS, based on the known nonlinear characteristics of rubber materials and the constitutive model of rubber materials, the influence of internal pressure on the rubber bushing of screw drilling tools and the influence of different Poisson's ratio on the rubber bushing of screw drilling tools are obtained. In order to guide the use of the screw drill and the preparation of NBR under relevant conditions.
\end{abstract}

Keywords - Screw drill, Screw drill, NBR (Acrylonitrilebutadiene rubber ) , Poisson ratio , Uniform pressure, ABAQUS , Finite element analysis

\section{INTRODUCTION}

Nowadays, most of the stator bushes of screw drilling tools are made of NBR (Acrylonitrile-butadiene rubber) ${ }^{[1][2]}$. NBR has become the first choice for stator bushes because of its unique wear resistance and high temperature compressibility. However, due to the fact that the drilling process is very complicated, when the screw drilling tool working under the high temperature, high pressure and high salt environment, the rubber bushing of the stator will be subjected to the effect of continuous and changeable shear stress and shear stress, so the rubber bushing of the stator will inevitably produce fatigue. Based on this situation, it is far from enough if we just ask for its physical characteristics. Because this long-term complex stress transformation will make the rubber internal heat and destroy its internal structure. With the changeable downhole temperature, screw drilling rubber bushing will occur obvious early fatigue and permanent deformation, which will reduce the elasticity of the bushing. leading to lossing of drilling fluid and power. It has a serious impact on drilling efficiency and cost.

According to the results of Market Research, nowadays, 5/6 screw drill is the main tool [3][4]. Due to the complicated working conditions of the underground, it is very difficult to measure the deformation of the bushing in practice. On the basis of related research, using the large nonlinear finite element analysis software ABAQUS to do finite element calculation for conventional stator bushing structure with different uniform pressure, different Poisson's ratio and different hardness. To analyse the influence of complex conditions on the write performance and output performance of motor rotor. Finite element simulation is used to obtain the deformation data of conventional stator bushing under different influence factors. Thus it can guide the selection of bushing interference, the optimization of linear structure, the improvement of stator bushing structure, the correct selection of stator bushing material and the manufacturing process of stator bushing, thereby reducing the probability of screw drill failure and prolonging its service life.

\section{NONLINEAR CHARACTERISTICS OF RUBBER MATERIALS}

\section{A. Overview of rubber materials}

The conventional bushing of the stator of the screw drill motor is usually made of oil-resistant NBR, which has the thermodynamic characteristics of shrinkage after heating opposite to the thermal expansion of solid.

NBR belongs to vulcanized rubber. It not only has strong elastic properties, especially in shear and compression conditions, but also has high strength. Generally, NBR has relatively high hardness and can adapt to most of the oil, liquid and gas environment, so it is widely used in the petroleum industry. Nitrile-butadiene rubber (NBR) can not be explained by a simple elastic modulus because its mechanical behavior has obvious nonlinear characteristics under large deformation. There are many constitutive models of large deformation rubber, and different constitutive models are suitable for different rubber materials.

\section{B. Rubber physical characteristics}

(1) Large deformation characteristics: the elastic modulus of rubber material is much smaller than that of metal, so the elastic deformation is generally very large.

(2) Non linear: mainly includes stress-strain relationship, large displacement deformation and surface contact problem.

(3) Incompressibility: The Poisson's ratio of rubber varies from 0.490 to 0.4999 . While the metal materials are generally varies from $0.25-0.33$. So rubber is easier to compress than metal. Relationship between Poisson's ratio and line strain is as follow :

$$
\mu=\frac{1}{\varepsilon}\left[1-\sqrt{\frac{1}{1+\varepsilon}}\right]
$$


Therefore, when the rubber is deformed, its volume is almost unchanged.

In general, the strain energy density function is used to characterize the mechanical properties of hyperelastic materials. The strain energy function can be approximately expressed as:

$$
W=W\left(I_{1}, I_{2}, I_{3}\right)
$$

$I_{1} 、 I_{2} 、 I_{3}--$ Green is three invariants of strain tensors, and :

$$
\begin{aligned}
& I_{1}=\lambda_{1}^{2}+\lambda_{2}^{2}+\lambda_{3}^{2} \\
& I_{2}=\lambda_{1}^{2} \lambda_{2}^{2}+\lambda_{2}^{2} \lambda_{3}^{2}+\lambda_{3}^{2} \lambda_{1}^{2} \\
& I_{3}=\lambda_{1}^{2} \lambda_{2}^{2} \lambda_{3}^{2}
\end{aligned}
$$

$\lambda_{1}, \lambda_{2}, \lambda_{3}-$ Three principal elongation.

From the perspective of pure mathematics, Rivlin derives the most general form of strain energy density function.

$$
W=\sum_{i, j, k=0}^{n} C_{i k}\left(I_{1}-3\right)^{i}\left(I_{2}-3\right)^{j}\left(I_{3}-3\right)^{k}
$$

$C_{i k}-$ Material constant

Rubber materials are generally considered incompressible.

$$
\begin{aligned}
& \text { So } I_{3}=1 \text {. can come down to: } \\
& W=\sum_{i, j=0}^{n} C_{i j}\left(I_{1}-3\right)^{i}\left(I_{2}-3\right)^{j}
\end{aligned}
$$

\section{B. constitutive model of rubber material}

\section{Mooney-Rivlin}

The model is suitable for the case where the strain is about $100 \%$ (tension) and 30\% (pressure). Compared with other options, the higher order Mooney-Rivlin option can obtain better approximation for the solution of larger strain. This option includes Mooney-Rivlin models of 2, 3, 5, or 9 parameters.

A.2 parameter model :

$$
W=c_{10}\left(\overline{I_{1}}-3\right)+c_{01}\left(\overline{I_{2}}-3\right)+\frac{1}{d}(J-1)^{2}
$$

$c_{10}, c_{01}, d$-Material constant.

\section{B.3 parameter model :}

$$
W=c_{10}\left(\overline{I_{1}}-3\right)+c_{01}\left(\overline{I_{2}}-3\right)+c_{11}\left(\overline{I_{1}}-3\right)\left(\overline{I_{2}}-3\right)+\frac{1}{d}(J-1)^{2}
$$

$c_{10}, c_{01}, c_{11}, d$-Material constant

C.5 parament model:

$$
\begin{aligned}
W= & c_{10}\left(\overline{I_{1}}-3\right)+c_{01}\left(\overline{I_{2}}-3\right)+c_{20}\left(\overline{I_{1}}-3\right)^{2} \\
& +c_{11}\left(\bar{I}_{1}-3\right)\left(\overline{I_{2}}-3\right)+c_{02}\left(\bar{I}_{1}-3\right)^{2} \frac{1}{d}(J-1)^{2}
\end{aligned}
$$

$c_{10}, c_{01}, c_{20}, c_{11}, c_{02}, d$-Material constant

\section{D.9 parament model:}

$$
\begin{aligned}
W & =c_{10}\left(\overline{I_{1}}-3\right)+c_{01}\left(\overline{I_{2}}-3\right)+c_{20}\left(\overline{I_{1}}-3\right)^{2}+c_{11}\left(\overline{I_{1}}-3\right)\left(\overline{I_{2}}\right. \\
& +c_{02}\left(\overline{I_{2}}-3\right)^{2}+c_{30}\left(\overline{I_{2}}-3\right)^{2}+c_{21}\left(\overline{I_{1}}-3\right)^{2}\left(\overline{I_{2}}-3\right) \\
& +c_{12}\left(\overline{I_{1}}-3\right)\left(\overline{I_{2}}-3\right)^{2}+c_{03}\left(\overline{I_{2}}-3\right)^{3}+\frac{1}{d}(J-1)^{2}
\end{aligned}
$$

$c_{10}, c_{01}, c_{20}, c_{11}, c_{02}, c_{30}, c_{21}, d$-Material

constant.

According to the Mooney-Rivlin two-parameter model, the elastic modulus E=11.49, the Poisson's ratio of rubber material is close to 0.499 , and the Poisson's ratio varies from 0.490 to 0.499 . The relationship between the shear modulus $\mathrm{G}$ or $\mathrm{E}$ and the material constant is $G=2\left(c_{10}+c_{01}\right)$ or $E=6\left(c_{10}+c_{01}\right)$.The value of the $c_{01}$ and $c_{10}$ is determined by experiments, and $c_{10}=1.879$ and $c_{01}=0.038$ are obtained by comparing the simulated and measured results.

\section{FINITE ELEMENT MODEL}

The physical and geometric parameters in the calculation model of conventional screw drill stator bushing are selected as follows: the inner cavity profile size of rubber bushing depends on the rotor radius $r$ and eccentricity e. According to the formula, the rotor radius $\mathrm{r}=38.5 \mathrm{~mm}$, eccentricity $\mathrm{e}=$ $8 \mathrm{~mm}$, elastic modulus of rubber bushing is 11.49 and poisson's ratio is 0.499 .

Finite element analysis of two-dimensional and threedimensional models in the literature shows that there is not much difference between them. Therefore, in order to improve the calculation efficiency, the analysis of stator bushing of $5 / 6$ screw drilling tools in this paper is also solved by plane 


\section{International Journal of Engineering Applied Sciences and Technology, 2019 Vol. 3, Issue 12, ISSN No. 2455-2143, Pages 17-21 \\ Published Online April 2019 in IJEAST (http://www.ijeast.com)}

According to proper simplification and treatment, a twodimensional finite element model of the stator is established as shown in fig. 3-1 above. A total of 1549 elements apply uniform internal pressure to the stator cavity.

Because the material of bushing outer ring is 45 steel, the deformation of bushing outer wall is less than that of stator bushing under the same internal pressure, so the bushing outer wall is regarded as rigid constraint in the analysis of bushing deformation.

\section{ANALYSIS OF CALCULATION RESULTS}

Figure 4-1 below shows the distribution of stress and strain of the stator when the inner wall of the rubber bush is subjected to a uniform internal pressure of $50 \mathrm{mpa}$. The dark part of the figure is 15 times as large as the deformation.

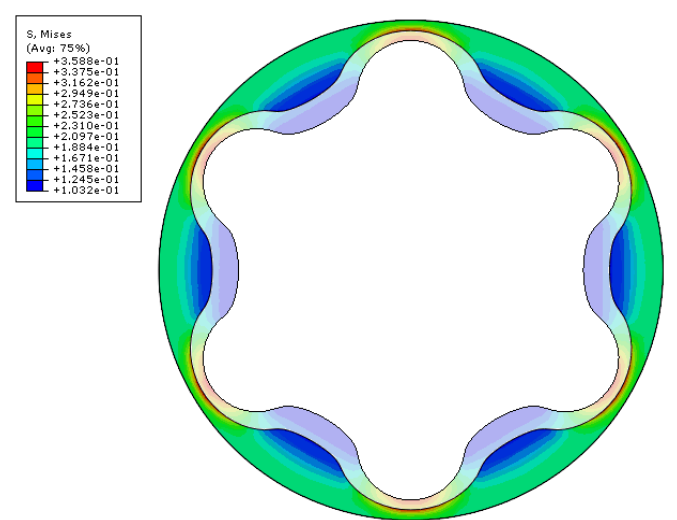

FIG 4-1 STRESS AND STRAIN DISTRIBUTION OF BUSHING

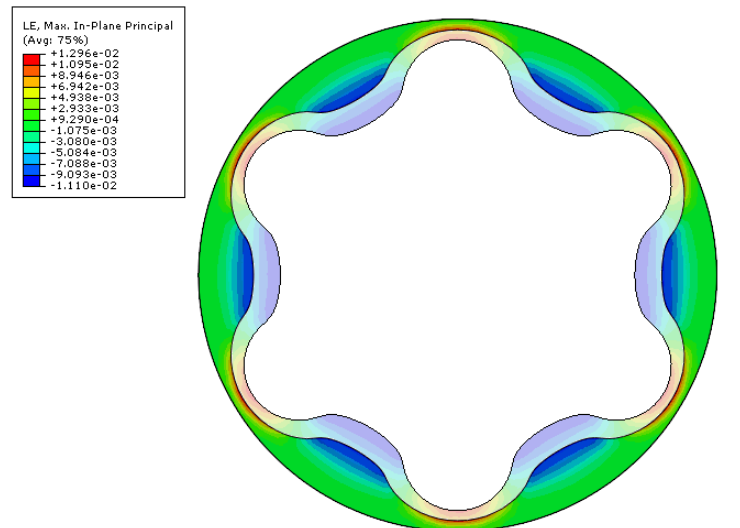

FIG. 4-2 SHEAR STRESS AND STRAIN DISTRIBUTION OF BUSHING

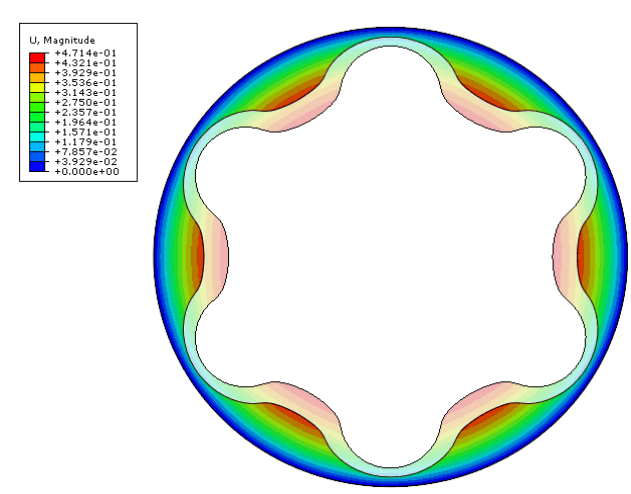

FIG. 4-3 DISTRIBUTION OF SHEAR STRESS AND DISPLACEMENT OF BUSHING

As can be seen from fig. 4-1 above, because the arc bottom part is relatively thin, the maximum stress and strain of stator bushing occur at the arc bottom, so the arc bottom part is prone to stress concentration. The stress and strain at the top of the arc are small, and the stress and strain change periodically from the top of the arc to the bottom of the arc. It is found from fig. 4-2 that the shear stress varies symmetrically along the axial direction. The maximum shear stress occurs at the outer boundary of the bushing, which may be related to the linetype and structure design of the bushing. From the displacement cloud figure 4-3, it can be seen that the maximum deformation is basically in the arc top, the thickness of the arc top bushing is larger, the deformation is larger than the arc bottom. Under the ideal condition of applying uniform pressure, all the performance parameters of rubber can meet the requirements.

Under the action of internal pressure, the stress and displacement of the inner contour of the bushing directly affect the selection of interference and sealing performance of the screw drill. Therefore, the analysis of the variation curves of stress and displacement is of great significance for the failure study of stator bushing.

\section{INFLUENCE OF INTERNAL PRESSURE INFLUENCE ON BUSHING LAW}

Figures 5-1 and 5-2 show that the inner surface of the bushing is subjected to uniform internal pressure 30, 40, 50, 60,70 and $80 \mathrm{MPa}$ respectively. The equivalent stress, shear stress and displacement of the inner contour of the bushing are distributed in the circumferential direction A-G-A ( Route $A, B, C, \ldots, J, K, L, A)$ of the inner ring. 


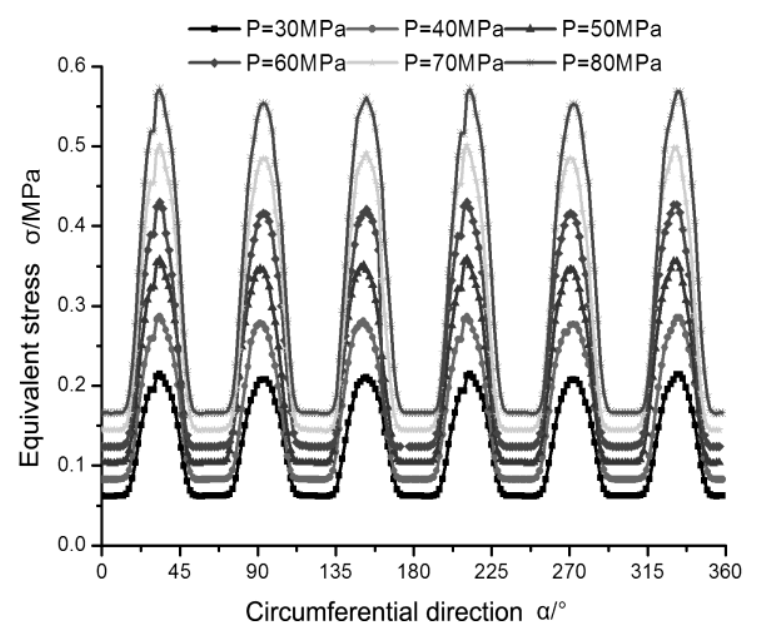

Fig.5-1 Distribution of equivalent stress with pressure under uniform pressure.

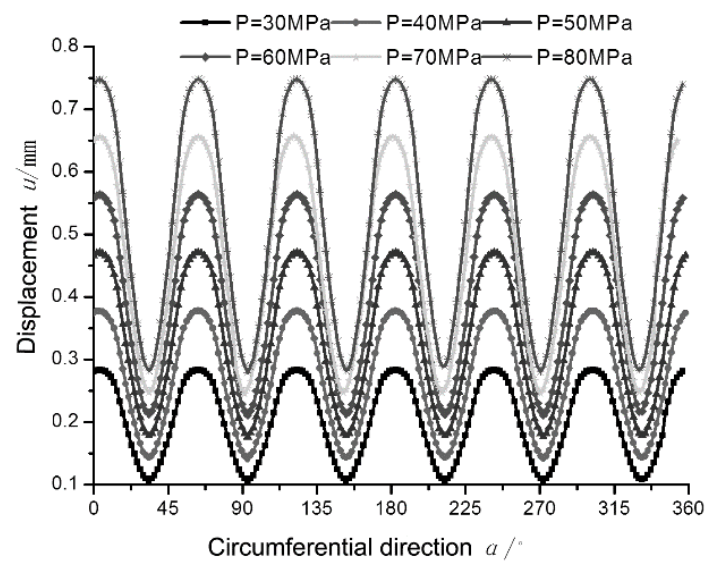

Fig.5-2 Distribution of displacement with pressure under uniform pressure

Under a certain internal pressure, all points on the inner contour line move outward, and the equivalent stress and displacement of each point are different. The maximum value of the equivalent stress is at the bottom of the arc, the minimum value is at the top of the arc, while the displacement value is just the opposite. The maximum value is at the top of the arc and the minimum value is at the bottom of the arc. This is related to the uneven thickness of the bushing. Stress and displacement change periodically, displacement change regularity is stronger, showing a positive spin law, a period of about six peaks and troughs. With the increase of pressure, the displacement and stress increase correspondingly, but the increase of pressure has little effect on the stress and displacement.

In practical application, the stator-rotor pair of screw motor needs to meet the sealing conditions, so the stator-rotor is often interference fit. The interference of the conventional $5 / 6$ screw drilling tools with the size of 172 is usually less than $0.5 \mathrm{~mm}$, which is mainly used for drilling the middle and deep wells. The static pressure is $40-50 \mathrm{MPa}$ at this time. The displacement of the bushing is about $0.284-0.378 \mathrm{~mm}$, and the temperature rise makes the rubber expand. The movement pair of the stator and rotor can basically seal. The pressure rises to $70-8$ at $5000-6000 \mathrm{~m}$ interval. At $0 \mathrm{MPa}$, the displacement of bushing reaches about $0.7-0.8 \mathrm{~mm}$. If the interference less than $0.5 \mathrm{~mm}$ is selected, the stator-rotor pair cannot be sealed. Therefore, in order to ensure the normal operation of the screw drilling tool, it is necessary to select a reasonable interference between the stator and rotor according to the well depth to reduce the probability of downhole accidents.

\section{INFLUENCE OF RUBBER POISSON RATIO ON BUSHING} LAW

In general analysis, rubber is often regarded as a volume incompressible material, but strictly speaking, NBR used in screw drills is similar to incompressible material, and the effect of its small compression on the mechanical properties of rubber structure can not be ignored. The Poisson's ratios of rubber generally vary between 0.490 and 0.499 . For this reason, rubber with $0.490,0.493,0.495,0.497$ and 0.499 Poisson's ratios are calculated under $50 \mathrm{MPa}$ uniform pressure, and the analysis results of these different Poisson's ratios are compared.

The distributions of stress and displacement along the path A-G-A along the bushing inner contour line of $0.490,0.493$, $0.495,0.497$ and 0.499 Poisson's ratios at $50 \mathrm{MPa}$ uniform pressure are shown in Fig. 6-1 and Fig. 6-2 below

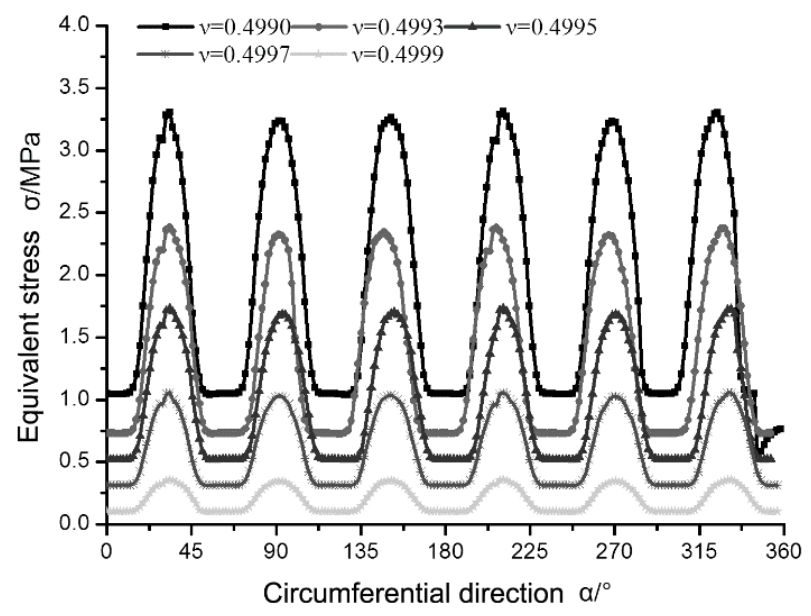

Fig. 6-1 distribution of equivalent stress with different pressure at Different Poisson's ratio 


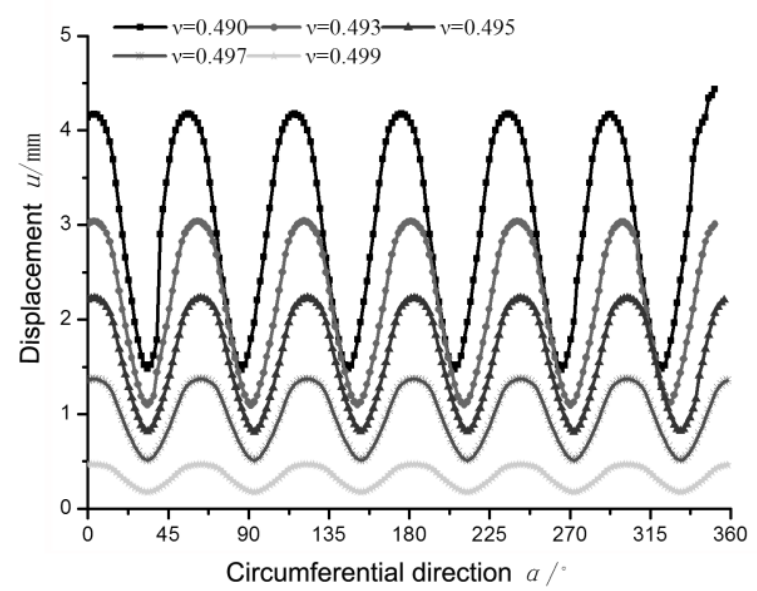

Fig. 6-2 distribution of displacement of Different Poisson's ratio with pressure

AS CAN BE SEEN FROM THE ABOVE GRAPHS, WITH THE increase of Poisson's ratio, the equivalent stress, shear stress and displacement all show a decreasing trend, and in the case of Poisson's ratio of 0.499 , the change of equivalent stress, shear stress and displacement is relatively small, in the case of Poisson's ratio below 0.495 , the maximum equivalent stress reaches more than 1.75 $\mathrm{MPa}$. The displacement is more than 2 $\mathrm{mm}$, the maximum shear stress is more than $1.25 \mathrm{MPa}$, and is under the action of uniform pressure. If there is pressure difference in the field, such a large deformation is not allowed. Therefore, too low Poisson's ratio will inevitably lead to sealing failure due to too large liner degeneration, thus affecting the working efficiency of screw drilling tools. Therefore, it is necessary to strictly control the injection process and properly select the rubber compound (usually choosing 0.499 Poisson's ratio of rubber material) to ensure the mechanical properties of vulcanized rubber.

\section{CONCLUSION}

(1) The two-dimensional model of the conventional screw drill rubber bushing is analyzed by using ABAQUS finite element analysis software, and the results of stress-strain and displacement nephogram are obtained. The fragile part of the stator rubber bushing and the maximum displacement change are obtained. The sealing property of rubber bushing was preliminarily verified, and the pre-tightening force data of motor stator rubber bushing were obtained.

(2) Finite element analysis is carried out under different uniform internal pressures, and the variation law of equivalent stress and linear displacement under different uniform pressures is obtained, which can be used to guide and conjecture the sealing operation in different depth drilling environment.

(3) Under the above conditions, the conventional NBR stator bushing with small difference in elastic modulus was deduced and analyzed. The equivalent stress and linear displacement under different Poisson's ratio were obtained by ABAQUS two-dimensional model. The results show that the rubber stator is well sealed at 0.499 Poisson's ratio. When the rubber Poisson's ratio falls below 0.495 , the drilling fluid will be leaked because of the large linear deformation caused by the excessive downhole pressure, which can guide the processing technology of the screw stator NBR bushing.

\section{REFERENCE:}

[1] Han Chuanjun Zhang.Jie Liu Yang. Thermal-structure coupling analysis for general stator lining of PDM[J]. Journal of Central SouthUniversity : Science and Technology ,2013,44(6) : 23H-2317.

[2] Liu He . Hao Xianzhong . Wang Liangang.et al. Current technicalstatus and development trend of artificial li!t[J]. Acta PetrolciSinica,20 15,36(H ) : 1441-1448.

[3] SHI Guo-chen . Theperformanceanalysisand thematching technologyre search ofprogressing cavity pump foroilproduction[D] . HarbinInstituteofTechnology , 2002. (in Chinese)

[4] YEW ei-dong , HAN Dao-quan , SONG Yu-jie , eta1.Contactingpressure analysisofstatorand rotorofprogressivecavity pumpEJ] . OilFieldEquipment , $2008,37(8): 25-28$. (in Chinese) 